\title{
EFFECT OF ELECTRON BEAM IRRADIATION ON THE TENSILE PROPERTIES OF OIL PALM MESOCARP FIBRE/POLY(BUTYLENE SUCCINATE) BIOCOMPOSITES
}

\author{
Y. Y. Then ${ }^{1 *}$, N.A. Ibrahim ${ }^{1}$, N. Zainuddin ${ }^{1}$, H. Ariffin ${ }^{2}$, W.M.Z. Wan Yunus ${ }^{3}$ and \\ M.F. Abd Rahman ${ }^{4}$
}

${ }^{1}$ Department of Chemistry, Faculty of Science, Universiti Putra Malaysia 43400 UPM Serdang, Selangor, Malaysia

*Email: yoonyeetyy84@yahoo.com

Phone: +60389466602; Fax: +60389432508

${ }^{2}$ Department of Bioprocess Technology

Faculty of Biotechnology and Biomolecular Sciences, Universiti Putra Malaysia,

43400 UPM Serdang, Selangor, Malaysia

${ }^{3}$ Department of Chemistry, Centre for Defence Foundation Studies

National Defence University of Malaysia, Sungai Besi Camp

57000 Kuala Lumpur, Federal Territory of Kuala Lumpur, Malaysia

${ }^{4}$ Radiation Processing Technology Division, Malaysian Nuclear Agency,

Bangi, 43000 Kajang, Selangor, Malaysia

\begin{abstract}
The present work deals with the utilization of oil palm mesocarp fibre (OPMF) and poly(butylene succinate) (PBS) to produce cost-effective biodegradable materials. The biocomposite was prepared from OPMF and PBS at a weight ratio of 70:30 via a melt blending technique without addition of any additive. This biocomposite showed relatively low tensile and water resistance properties. As a consequence, it was subjected to electron beam irradiation (EBI) treatment under various irradiation dosages ranging from 5-25 kGy, aiming at improving both its tensile properties and its water resistance. The results indicated that the biocomposite irradiated with $25 \mathrm{kGy}$ of applied dosage showed a considerable improvement of 50\% in tensile strength, $780 \%$ in tensile modulus and $38 \%$ in elongation at break. The water absorption and thickness swelling of the biocomposites were reduced after EBI treatment. The scanning electron microscopy showed improvement of the interfacial adhesion between OPMF and PBS after EBI treatment.
\end{abstract}

Keywords: Biocomposites; electron beam irradiation; poly(butylene succinate); oil palm mesocarp fibre

\section{INTRODUCTION}

Recently, natural fibre-filled polymer biocomposites have been increasingly utilized as an alternative to glass fibre-filled polymer composites in the automotive and construction industries due to their eco-friendliness, light weight and energy-saving characteristics [1]. Malaysia is one of the major oil palm plantation countries in the world, hence a huge amount of biomass is generated after the production of palm oil. Statistical analysis showed that approximately $4 \mathrm{~kg}$ of dry biomass is generated with every kilogram of palm oil produced. Oil palm mesocarp fibre (OPMF) is one of the 
types of biomass generated in the palm oil mill after the extraction of oil from the oil palm fruit [2]. In 2010, the available amount of OPMF in Malaysia was reported to be $10.80 \mathrm{Mt}$ [3]. Currently, it is either used in mulching or incinerated to generate electricity for the mill, but both these methods are detrimental to the environment, so a more sustainable method is required. Therefore, utilization of OPMF as a filler for biocomposites fabrication may play a key role in reducing the problem and at the same time produce a value-added product. Poly(butylene succinate) (PBS) is a commercially available biodegradable polymer produced from monomers of 1,4-butanediol and succinic acid via the polycondensation process [2]. Traditionally, those monomers are derived from a petroleum-based system, but nowadays they can be produced from renewable resources via a bacterial fermentation route [3]. This means that PBS has received equal attention to that given to other biodegradable polymers such as poly(lactic acid) (PLA) and poly(hydroxyl butyrate) (PHB), which are also derived from renewable resources. In comparison to PLA and PHB, PBS is relatively ductile and flexible in nature, with low rigidity, which has made it more suitable for various applications [4-8].

The biodegradability, renewability, availability and low cost of natural fibre have made it an attractive filler for biocomposites fabrication $[9,10]$. However, its high moisture adsorption, relatively poor wettability and compatibility with some polymeric matrices have restricted many of its applications [6, 11-15]. Therefore, various treatment methods such as silane, alkali, peroxide, and isocyanate are employed to modify the surface of natural fibres [11]. These treatments are less environmentally friendly as they always involve the use of solvents and wastes are generated at the end of the process. Additionally, the solvents and chemicals used are expensive. Therefore, it would be desirable if an efficient and more environmentally friendly treatment process could be made available for improving the fibre/polymer interfacial adhesion. Recently, the electron beam irradiation (EBI) technique has been increasingly utilized for surface-modification and properties enhancement of various polymer materials like fibres, films and composites, as it is a dry, clean and cold process that is energy-saving, high speed and eco-friendly [16]. According to Han et al. [16], EBI treatment of natural fibre surfaces at certain dosages can significantly contribute to the improvement of the interfacial and mechanical properties as well as the thermal stability of natural fibre/polymer biocomposites. Therefore, there is no doubt that EBI treatment can be used in this work to enhance the properties of OPMF/PBS biocomposite. This paper highlights the effect of EBI treatment on the tensile and water absorption behaviours of OPMF/PBS biocomposite without the presence of any additive. The adhesion between OPMF and PBS was studied using scanning electron microscopy.

\section{EXPERIMENTAL SET-UP}

\section{Materials}

Poly(butylene succinate) (PBS), under the commercial name of BIONOLLE 1903MD, was purchased from Showa Denko, Japan. It has a density of $1.26 \mathrm{~g} / \mathrm{cm}^{3}$ and a melting point of $\sim 115{ }^{\circ} \mathrm{C}$. Its molecular structure is shown in Figure 1. OPMF was collected from FELDA Serting Hilir Oil Palm Mill, Malaysia. It was first soaked in distilled water for 24 hours, then rinsed with hot water $\left(60{ }^{\circ} \mathrm{C}\right)$ and acetone prior to drying at $60{ }^{\circ} \mathrm{C}$ in an oven. This process was carried out to remove waxes and impurities from the fibre 
surface. The dried fibre was then ground, sieved into sizes of 150-300 $\mu \mathrm{m}$ and stored in a sealed polyethylene bag for use in biocomposite fabrication.

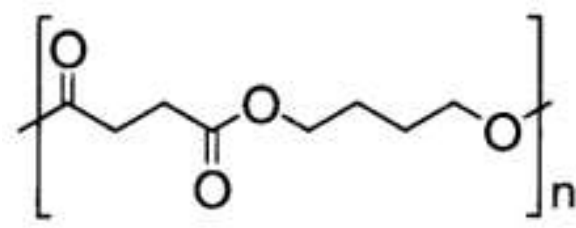

Figure 1. Molecular structure of PBS.

\section{Fabrication of OPMF/PBS Biocomposite}

Before processing, both PBS and OPMF were oven dried at $60{ }^{\circ} \mathrm{C}$. The OPMF/PBS biocomposite was fabricated by melt blending of PBS and OPMF in a Brabender internal mixer at $120{ }^{\circ} \mathrm{C}$ with $50 \mathrm{rpm}$ rotor speed for 15 minutes. The weight ratio of OPMF/PBS was fixed at 70:30. PBS was first loaded into the heating chamber for $2 \mathrm{~min}$ to melt. After that, OPMF was added slowly into the heating chamber and mixing continued for another $13 \mathrm{~min}$. This compounded material was then compressed into a 1 $\mathrm{mm}$ sheet by a hydraulic hot press also at $120{ }^{\circ} \mathrm{C}$ under a pressure of $150 \mathrm{~kg} / \mathrm{cm}^{2}$ for 5 min, followed by cold pressing at $30{ }^{\circ} \mathrm{C}$ for $5 \mathrm{~min}$.

\section{Electron Beam Irradiation}

Electron beam irradiation treatment was carried out using an electron beam machine, EPS Model-3000. Before treatment, the previously compressed sample sheets were put in a polyethylene bag and vacuum-sealed. The samples were then placed on an aluminium tray and irradiated at room temperature within a dosage range of 5-25 kGy at $5 \mathrm{kGy} /$ pass with accelerator energy of $1 \mathrm{MeV}$, beam current of $2 \mathrm{~mA}$ and conveyor speed of $0.94 \mathrm{~m} / \mathrm{min}$. One-sided irradiation was employed for all the samples.

\section{Tensile Properties Measurement}

Tensile testing was carried out using a Universal Testing Machine, Instron 4302. The specimens for the tensile test were cut according to ASTM D638-5. The tensile test was performed at $25{ }^{\circ} \mathrm{C}$ under a load cell of $1 \mathrm{kN}$ and crosshead speed of $5 \mathrm{~mm} / \mathrm{min}$. The results were expressed in terms of tensile strength, tensile modulus and elongation at break. Five specimens were tested for each group and their average values were reported.

\section{Scanning Electron Microscopy}

The scanning electron micrographs of the tensile fracture surfaces of biocomposites were captured using a JEOL JSM-6400 scanning electron microscope operated at $15 \mathrm{kV}$. The scanning electron micrographs were captured at a magnification of 200x. All the samples were coated with gold by a Bio-rad coating system before viewing to avoid charging of samples. 


\section{Water Absorption Test}

A water absorption test was conducted according to ASTM D570. The samples were cut to dimensions of $10 \times 10 \times 1 \mathrm{~mm}^{3}$ to perform the test. Prior to the water absorption test, the samples were oven dried at $60{ }^{\circ} \mathrm{C}$ until constant weight was obtained and denoted as $W_{0}$. The samples were then immersed in distilled water at $25{ }^{\circ} \mathrm{C}$. The samples were removed from the distilled water periodically, wiped with tissue paper to remove excess water on their surface and weighed immediately to obtain the wet weight $\left(W_{t}\right)$. After the weighing process, the samples were returned into the distilled water. This process was repeated up to 168 hours. Three specimens were tested for each set of experiments and their average values were reported. The water uptake was calculated based on Eq. (1):

$$
\text { Water uptake }(\%)=\frac{W_{t}-W_{0}}{W_{0}} \times 100 \%
$$

\section{Thickness Swelling Test}

The thickness swelling test was conducted according to the European Standard EN 317 (1993). Samples with dimensions of $10 \times 10 \times 1 \mathrm{~mm}^{3}$ were cut and used to carry out the test. The samples were oven dried at $60{ }^{\circ} \mathrm{C}$ prior to analysis. The thickness of the samples was measured before immersion in distilled water for 24 hour at $25{ }^{\circ} \mathrm{C}$. This initial thickness was denoted as $T_{0}$. After that, the samples were removed from the distilled water and wiped with tissue paper to remove excess water on their surface. The thickness of the wet samples $\left(T_{24 h}\right)$ was measured immediately. Three specimens were tested for each set of experiments and their average values were reported. The thickness swelling was calculated based on Eq. (2):

$$
\text { Thickness swelling }(\%)=\frac{T_{24 h}-T_{0}}{T_{0}} \times 100 \%
$$

\section{RESULTS AND DISCUSSION}

In previous work [17], we have reported the maximum amount of OPMF that can be incorporated into the biocomposite of OPMF/PBS to be $70 \mathrm{wt} \%$. Therefore, this ratio was chosen in this study to evaluate the effect of EBI treatment on the tensile and water resistance properties of this biocomposite without applying any additive.

\section{Tensile Properties}

The tensile test is carried out to study the effectiveness of EBI treatment in tuning the tensile properties of OPMF/PBS biocomposite. The tensile strength, tensile modulus and elongation at break of OPMF/PBS biocomposite as a function of EBI dosages are illustrated in Figures 2, 3 and 4, respectively. The tensile strength of non-irradiated OPMF/PBS biocomposite shows a value of $13.86 \mathrm{MPa}$ (Figure 2). This value increased gradually with increasing EBI dosages. The maximum increment is observed at an EBI dosage of $25 \mathrm{kGy}$, which shows a value of $21.50 \mathrm{MPa}$ or an improvement of $50 \%$ relative to non-irradiated OPMF/PBS biocomposite. During EBI treatment, several reactions may occur in the polymer microstructure, such as chain-scission, cross-linking, 
and recombination of broken chains. Additionally, dislocating or abstracting of hydrogen atoms from the polymer chain may also happen [18]. The sites where hydrogen has been abstracted can instantly be joined with adjacent molecular chains to form strong bonds. According to Suhartini et al. [19], PBS does not cross-link within the EBI dosage range of this study. Therefore, the enhancement in tensile strength of $\mathrm{OPMF} / \mathrm{PBS}$ biocomposite is mainly due to the formation of chemical bonds between the polymer matrix and fibre [20].

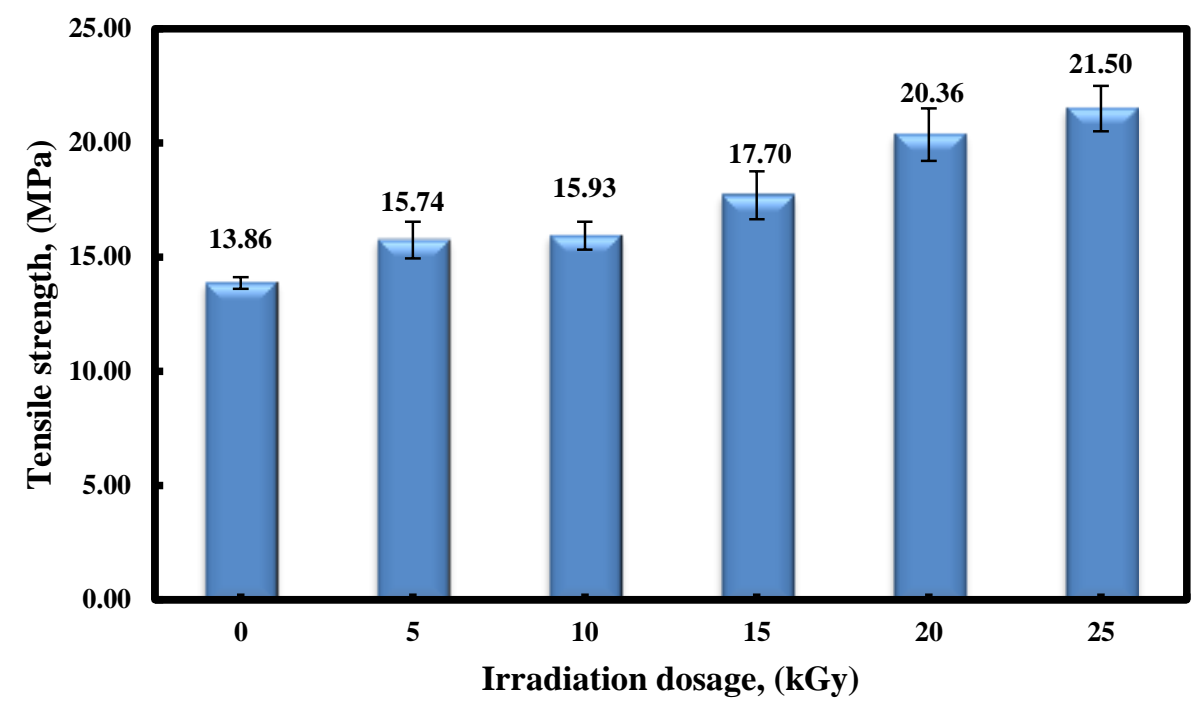

Figure 2. Tensile strength of OPMF/PBS biocomposites at different irradiation dosages.

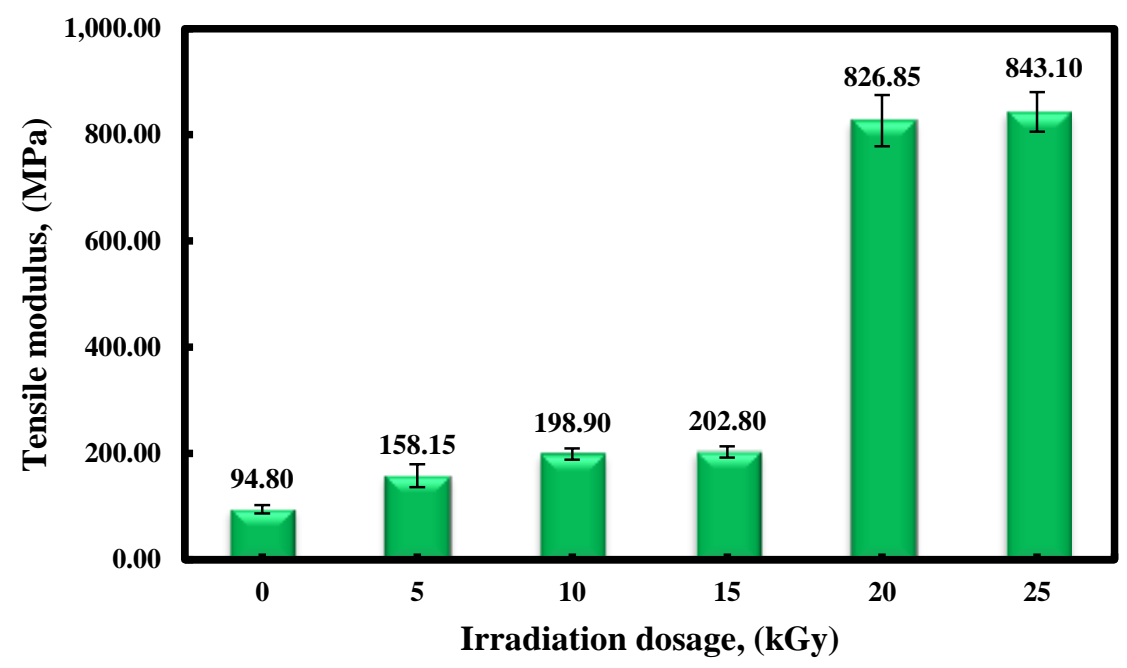

Figure 3. Tensile modulus of OPMF/PBS biocomposites at different irradiation dosages.

An increasing trend is also observed for the tensile modulus upon EBI treatment, as shown in Figure 3. The tensile modulus of OPMF/PBS biocomposite increases gradually with increasing EBI dosages of up to $15 \mathrm{kGy}$. A drastic increment in tensile modulus is observed at an EBI dosage of $20 \mathrm{kGy}$. Beyond that $(25 \mathrm{kGy})$, the increment is rather small. At low EBI dosages $(5-15 \mathrm{kGy})$, fewer radicals are generated due to insufficient energy, hence a limited reaction occurs. However, once a suitable dosage (20 kGy) is applied, a reaction may occur rapidly owing to the presence of a large 
amount of free radicals. After that, it reaches a plateau region $(25 \mathrm{kGy})$ before degradation of chains starts to occur at higher EBI dosages. Figure 3 shows that the tensile modulus of non-irradiated OPMF/PBS biocomposite is $94.80 \mathrm{MPa}$ and it has increased to a value of $843.10 \mathrm{MPa}$ after EBI treatment at $25 \mathrm{kGy}$, showing an improvement of $780 \%$. Previous studies by Ahmad et al. [21] also reported an increase in tensile modulus with increasing irradiation dosages and a decrease at higher irradiation dosages. It is interesting to note that the elongation at break of the irradiated biocomposite is enhanced by $38 \%$ upon EBI treatment at $25 \mathrm{kGy}$, as shown in Figure 4. This observation can probably be attributed to the better bridging formed at the interfacial region, by either a van der Waals interaction or a covalent bond between the PBS and OPMF after irradiation. The improved interfacial adhesion between OPMF and PBS (clearly shown in Figure 5(b)) will then prolong the deformation of the biocomposite, resulting in a higher value of elongation at break.

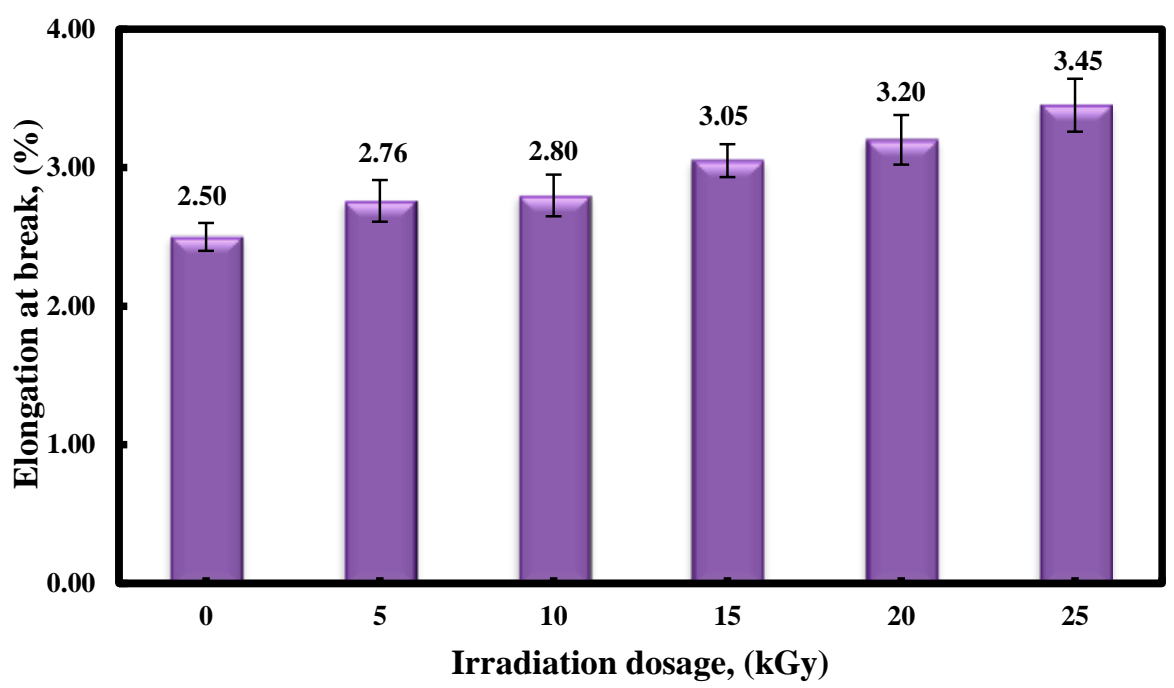

Figure 4. Elongation at break of OPMF/PBS biocomposites at different irradiation dosages.

\section{Surface Morphology}

SEM analysis is performed on the tensile fracture surfaces for direct observation of the biocomposite structure, particularly to examine the degree of adhesion at the fibre/polymer interface region. The SEM micrographs of non-irradiated and irradiated OPMF/PBS biocomposites are shown in Figure 5. The SEM micrograph of nonirradiated OPMF/PBS biocomposite (Figure 5(a)) shows a two-phase system, with numerous voids present on the fracture surface due to the detachment of OPMF from the PBS matrix. Additionally, visible gaps can also be seen at the interface of the OPMF and PBS, resulting from poor interfacial adhesion between the hydrophilic OPMF and hydrophobic PBS. It is noted that the surface of the OPMF is relatively clean with no PBS adhering on it during fibre pull-out, indicating that their bonding is relatively poor. An obvious morphological change is observed upon EBI treatment at $25 \mathrm{kGy}$ (Figure 5(b)). The interfacial adhesion between OPMF and PBS appears to be improved after EBI treatment. This is clearly manifested by the presence of fewer voids and the disappearance of visible gaps between the OPMF and PBS. In addition, the PBS also seems to be adhered on the surface of the OPMF during fibre pull-out (white circle in 
Figure 5(b)), indicating that their bonding strength is relatively stronger. This result coincides with the results for tensile strength, tensile modulus and elongation at break of biocomposites, which show improvement after EBI treatment.
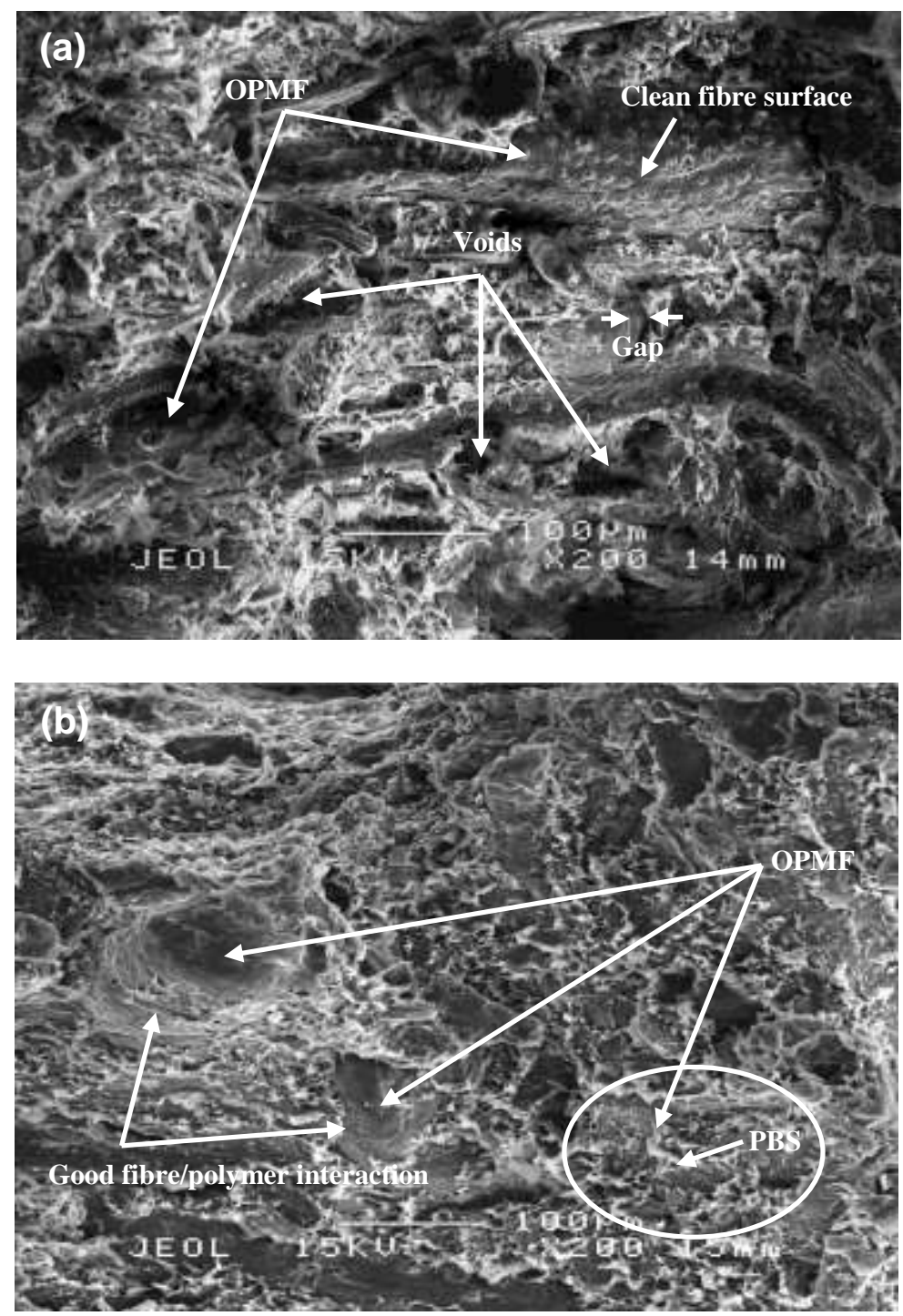

Figure 5. SEM micrographs of (a) non-irradiated OPMF/PBS and (b) irradiated $\mathrm{OPMF} / \mathrm{PBS}$ at $25 \mathrm{kGy}$.

\section{Water Absorption}

Water absorption is one of the major concerns in polymer/fibre biocomposite for industrial application, since natural fibre is hydrophilic in nature and very sensitive to moisture. For this reason, a water absorption test is carried out to study the effect of EBI treatment on the water absorption behaviour of the OPMF/PBS biocomposite. The water absorption of non-irradiated and irradiated OPMF/PBS biocomposites as a function of immersion time in water is graphically displayed in Figure 6. Both biocomposites show an increase in water absorption with prolonged immersion time in water. The increase in water absorption is probably due to the hydrophilic nature of OPMF, which contributes to water absorption $[22,23]$. Non-irradiated OPMF/PBS biocomposite shows higher 
water absorption than that of irradiated OPMF/PBS biocomposites. This is because the gaps present at the interface of OPMF/PBS biocomposite may also act as a pathway to water absorption [24]. The water absorption of OPMF/PBS biocomposite at 168 hours is reduced from 25.41 to $14.61 \%$ after EBI treatment at $25 \mathrm{kGy}$, showing a $43 \%$ reduction. The improvement in interfacial adhesion between the OPMF and PBS may be the reason for the decrease in water absorption after EBI treatment. A similar observation has also been reported by other researchers [25, 26].

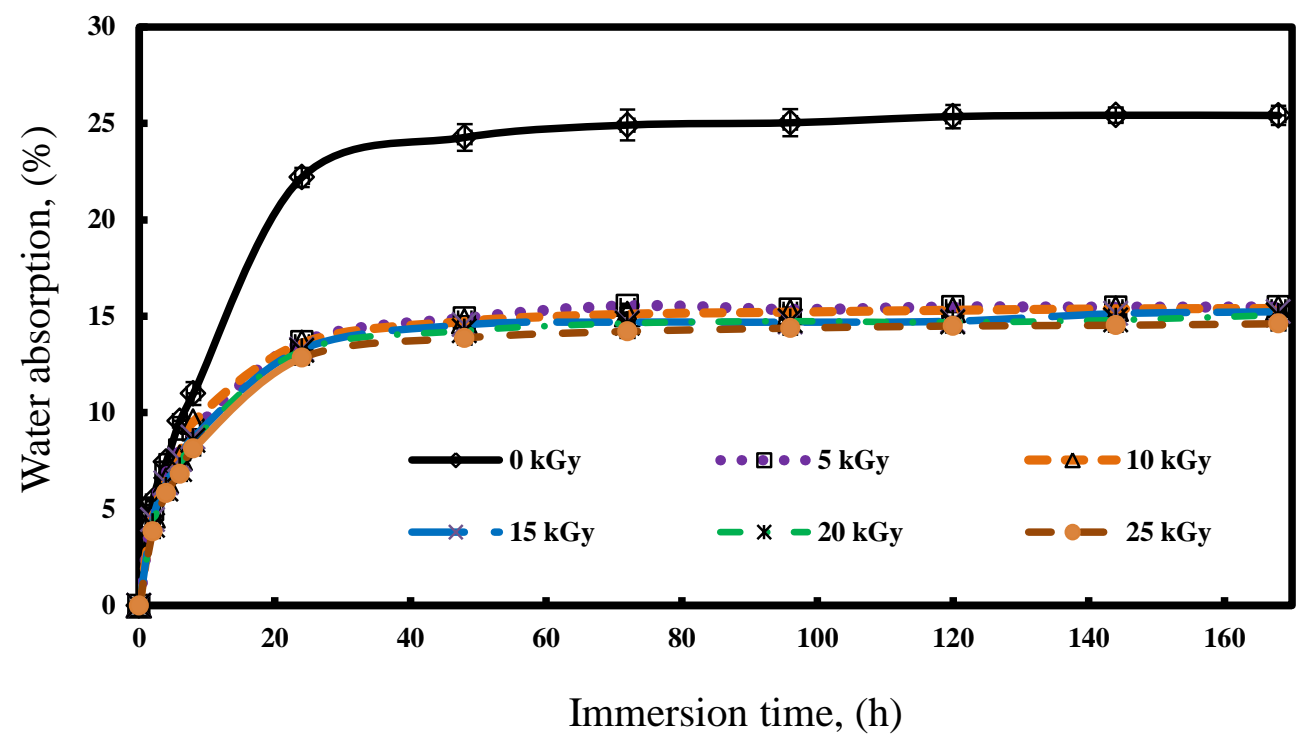

Figure 6. Water absorption of non-irradiated and irradiated OPMF/PBS biocomposites at different immersion times.

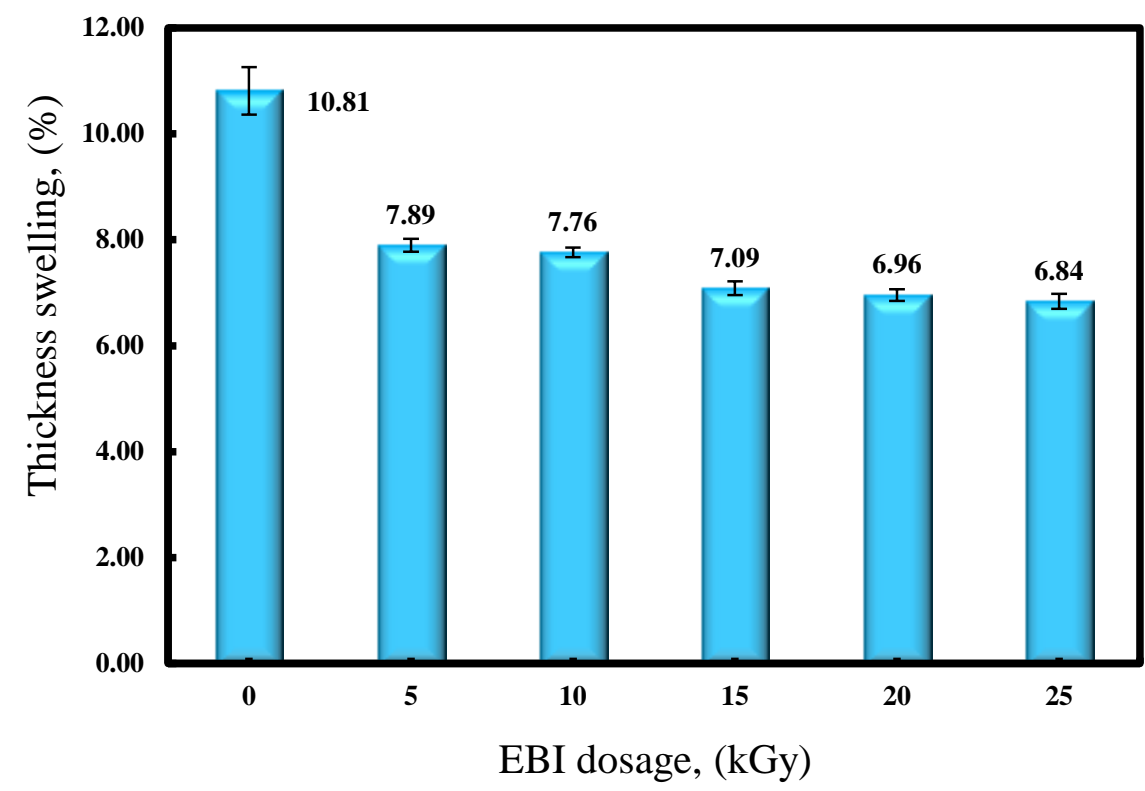

Figure 7. Thickness swelling of non-irradiated and irradiated OPMF/PBS biocomposite after 24 hours of immersion in distilled water. 


\section{Thickness Swelling}

The thickness swelling test is conducted to study the dimensional stability of OPMF/PBS biocomposite in the presence of water. Figure 7 shows the thickness swelling of non-irradiated and irradiated OPMF/PBS biocomposites after immersion in water for 24 hours. It indicates that the thickness swelling of the OPMF/PBS biocomposite decreases with increasing EBI treatment dosages. The initial thickness swelling value $(10.81 \%)$ of the OPMF/PBS biocomposite is reduced to $6.84 \%$ upon EBI treatment at $25 \mathrm{kGy}$, showing a $37 \%$ reduction. This is attributed to the decrease in water absorption of the OPMF/PBS biocomposite after EBI treatment, as thickness swelling is proportional to the amount of water absorbed.

\section{CONCLUSIONS}

Electron beam irradiation was successfully employed to modify the tensile properties, water absorption and thickness swelling of OPMF/PBS biocomposite. The tensile strength, tensile modulus and elongation at break of the OPMF/PBS biocomposite were improved considerably after electron beam irradiation treatment at an applied dosage of $25 \mathrm{kGy}$. The electron beam irradiation treatment successfully reduced the water absorption and thickness swelling of the OPMF/PBS biocomposites by 43 and 37\%, respectively. The interfacial adhesion between the OPMF and PBS was improved after treatment with electron beam irradiation.

\section{ACKNOWLEDGEMENTS}

The first author would like to acknowledge Ministry of Education Malaysia for the provision of scholarship (MyPhd). The authors wish to thank all technical staffs in the Department of Chemistry, Faculty of Science, Universiti Putra Malaysia for their kind assistance.

\section{REFERENCES}

[1] Abdul Majid MS, Daud R, Afendi M, Amin NAM, Cheng EM, Gibson AG, et al. Stress-strain response modelling of glass fibre reinforced epoxy composite pipes under multiaxial loadings. Journal of Mechanical Engineering and Sciences. 2014;6:916-28.

[2] Kim H-S, Kim H-J, Lee J-W, Choi I-G. Biodegradability of bio-flour filled biodegradable poly (butylene succinate) bio-composites in natural and compost soil. Polymer Degradation and Stability. 2006;91:1117-27.

[3] Babu RP, O'Connor K, Seeram R. Current progress on bio-based polymers and their future trends. Prog Biomater. 2013;2:1-16.

[4] Liu L, Yu J, Cheng L, Yang X. Biodegradability of poly (butylene succinate)(PBS) composite reinforced with jute fibre. Polymer Degradation and Stability. 2009;94:90-4.

[5] Hafizi ZM, Epaarachchi J, Lau KT. An investigation of acoustic emission signal attenuation for monitoring of progressive failure in fiberglass reinforced composite laminates. International Journal of Automotive and Mechanical Engineering. 2013;8:1442-56. 
[6] Jeffrey KJT, Tarlochan F, Rahman MM. Residual strength of chop strand mats glass fiber/epoxy composite structures: Effect of temperature and water absorption. International Journal of Automotive and Mechanical Engineering. 2011;4:504-19.

[7] Ravi Sankar H, Srikant RR, Vamsi Krishna P, Bhujanga Rao V, Bangaru Babu P. Estimation of the dynamic properties of epoxy glass fabric composites with natural rubber particle inclusions. International Journal of Automotive and Mechanical Engineering. 2013;7:968-80.

[8] Shah LH, Bun T, Nagata S, Shikama T. The effects of gamma-ray on the mechanical properties of Zr-based bulk metallic glass. International Journal of Automotive and Mechanical Engineering. 2012;6:713-21.

[9] Manning R, Ewing J. Temperature in cars survey. Royal Automobile Club of Queensland Limited (RACQ) Vehicle Testing Authority Brisbane, Australia. 2009.

[10] Wambua P, Ivens J, Verpoest I. Natural fibres: can they replace glass in fibre reinforced plastics? composites science and technology. 2003;63:1259-64.

[11] Kalia S, Kaith B, Kaur I. Pretreatments of natural fibers and their application as reinforcing material in polymer composites - a review. Polymer Engineering \& Science. 2009;49:1253-72.

[12] Riccieri J, Vázquez A, De Carvalho LH. Interfacial properties and initial step of the water sorption in unidirectional unsaturated polyester/vegetable fiber composites. Polymer Composites. 1999;20:29-37.

[13] Hariprasad T, Dharmalingam G, Praveen Raj P. Study of mechanical properties of banana-coir hybrid composite using experimental and fem techniques. Journal of Mechanical Engineering and Sciences. 2013;4:518-31.

[14] Ibrahim MS, Sapuan SM, Faieza AA. Mechanical and thermal properties of composites from unsaturated polyester filled with oil palm ash. Journal of Mechanical Engineering and Sciences. 2012;2:133-47.

[15] Adebisi AA, Maleque MA, Rahman MM. Metal matrix composite brake rotor: Historical development and product life cycle analysis. International Journal of Automotive and Mechanical Engineering. 2011;4:471-80.

[16] Han SO, Cho D, Park WH, Drzal LT. Henequen/poly (butylene succinate) biocomposites: electron beam irradiation effects on henequen fiber and the interfacial properties of biocomposites. Composite interfaces. 2006;13:231-47.

[17] Then YY, Ibrahim NA, Zainuddin N, Ariffin H, Wan Yunus WMZ. Oil Palm Mesocarp Fiber as New Lignocellulosic Material for Fabrication of Polymer/Fiber Biocomposites. International Journal of Polymer Science. 2013;2013.

[18] Makhlis FAe. Radiation physics and chemistry of polymers; Radiatsionnaya fizika i khimiya polimerov. 1972.

[19] Suhartini M, Mitomo H, Yoshii F, Nagasawa N, Kume T. Radiation crosslinking of poly (butylene succinate) in the presence of inorganic material and its biodegradability. Journal of Polymers and the Environment. 2001;9:163-71.

[20] Ratnam CT, Raju G, Yunus WMZW. Oil palm empty fruit bunch (OPEFB) fiber reinforced PVC/ENR blend-electron beam irradiation. Nuclear Instruments and Methods in Physics Research Section B: Beam Interactions with Materials and Atoms. 2007;265:510-4.

[21] Ahmad A, Mohd DH, Abdullah I. Electron beam cross-linking of NR/LLDPE blends. Iranian Polymer Journal. 2005;14:505-10. 
[22] Khoo S, Ismail Z, Kong K, Ong Z, Noroozi S, Chong W, et al. Impact force identification with pseudo-inverse method on a lightweight structure for underdetermined, even-determined and over-determined cases. International Journal of Impact Engineering. 2014;63:52-62.

[23] Islam MN, Rahman MR, Haque MM, Huque MM. Physico-mechanical properties of chemically treated coir reinforced polypropylene composites. Composites Part A: Applied Science and Manufacturing. 2010;41:192-8.

[24] Karmaker A. Effect of water absorption on dimensional stability and impact energy of jute fibre reinforced polypropylene. Journal of materials science letters. 1997;16:462-4.

[25] Nam TH, Ogihara S, Nakatani H, Kobayashi S, Song JI. Mechanical and thermal properties and water absorption of jute fiber reinforced poly (butylene succinate) biodegradable composites. Advanced Composite Materials. 2012;21:241-58.

[26] Han YH, Han SO, Cho D, Kim H-I. Dynamic mechanical properties of natural fiber/polymer biocomposites: the effect of fiber treatment with electron beam. Macromolecular Research. 2008;16:253-60. 